\title{
Tourist scams: exploring the dimensions of an international tourism phenomenon
}

\author{
Philip L. Pearce ${ }^{1 *}$
}

Received: 30/01/2011 Accepted: 05/04/2011

\footnotetext{
${ }^{1}$ Foundation Professor of Tourism, School of Business, James Cook University, Townsville, Queensland, Australia 4811; tel: 6147814762; fax: 6147814019; email: Philip.pearce@jcu.edu.au

* Corresponding author
}

\begin{abstract}
Tourist scams exist in many countries and are a subset of the long standing research area concerned with crimes against tourists. In this paper it is suggested that a defining feature of the tourist scam is the initial involvement of the tourist in the activity either through their gullibility or personal desire for an unusual or easy gain. This paper locates tourist scams in the literature on crimes against tourists and reviews work on scams in order to develop a category scheme portraying these encounters. Data collected in Thailand provide examples of scams to underpin the construction of a scheme which identifies tourist service scams, general retail scams and social interaction scams. The attribution of responsibility literature is used to interpret how scam victims are seen. A role for international comparative studies is suggested to better explain and potentially limit scam practices.
\end{abstract}

(C) 2011 International University College. All rights reserved

Keywords: tourist scams, crime, attribution, responsibility, Thailand, international comparisons

Citation: Pearce, P.L., (2011) Tourist scams: exploring the dimensions of an international tourism phenomenon. European Journal of Tourism Research 4(2), pp. 147-156

\section{Introduction}

A tourist scam for the purposes of this research will be defined as essentially fraudulent practice intended to gain financial advantage from a tourist where that targeted individual is initially a willing participant (Pearce, 2011). Not all scams are illegal. Many scams do, however, involve barely legal behaviours and include instances of deception, false promises and ruses designed to extort cash or goods from the target. Tourist scams exist in many countries and while the forms differ outwardly, it will be suggested that the principles of exploiting tourists are similar. The aim of this research is to provide an understanding of the situations and principles which underlie tourist scams. This task is approached through several steps. First, the studies on tourist scams will be set in the context of existing work concerned with crimes against tourists. Next the studies specifically focusing on tourist scams will be considered. A third section will identify some primary data on scams collected in one tourism setting - that of Bangkok, Thailand. The purpose of this primary data is to provide material which can be applied to a 
wider set of global tourist scams. Finally, the issue of responsibility will be considered as a special concern in the area of tourist scams. It follows from the organising definition already cited that scams are possible because tourists, like many other individuals, are initially at least partly to blame for the trouble in which they find themselves. The psychological work on attribution theory which deals with puzzling or ambiguous conduct will be used as the major conceptual and theoretical tool to develop the fuller understanding of the evolution of tourist scams and, potentially, ways to avoid them

\section{Literature Review}

\section{Crimes against tourists}

Tourist scams may be seen as a subset of the concern with crimes against tourists. The latter area of study has been a concern amongst tourist researchers for a considerable period of time (Chesney-Lind and Lind, 1986). One line of work in this field considers the documentation of crimes against tourists while a second strand of inquiry has pursued explanations of the observed patterns. Much of the work on crimes against tourists is built on statistics kept by local police departments. The data they collect is then aggregated into regional and national figures. The categories used in these studies of crime perception and crime statistics are informed by the kind of definition of crime offered by Ryan (1993); that is, crime consists of "actions contrary to written or case law applying either in the tourist generating or the tourist receiving country" (Ryan,1993: 174). Further, the crime based statistics are subdivided into what are referred to as the Big Six categories-murder and aggravated assault, rape, public violence, burglary, robbery and car theft.

Data from diverse locations confirm some common patterns about the problems to which tourists are exposed and have to endure (Pizam and Mansfeld, 1996, 2006; George, 2010). It is consistent with data from Hawaii and the Caribbean, as well as West and South Africa, that tourists are four to six times more likely to be robbed or burgled than encounter the other extremely negative experiences (Chesney-Lind and Lind, 1986; de Albuquerque and McElroy, 1999; Ferreira, 1999; George,
2003). Data from Eastern Europe are also aligned with these patterns. Michalko (2003) provides evidence from Hungary which suggests that some nationalities are probably less cautious in their tourist behaviour. He analysed the nationalities of crime victims in Hungary and found that German and Austrian tourists were more likely to be burglary victims compared to the tourists from neighbouring Eastern European countries. Michalko's explanation was two fold: tourists from the Western Europe are more affluent making them better targets but they may also be more careless since they are less used to the high levels of crime still persisting in some Eastern European nations.

Nevertheless data about crime rates are subject to error. Much criminal activity goes unreported and key organisations providing the data may have strong interests in representing information in ways that favour their efforts to reduce crime (Ambinder, 1992). At an even broader level, while any criminal activity against tourists is too much activity, the number of tourists who fall prey to criminal activity needs also to be put in the context of the millions of safe and relatively uneventful tourist trips undertaken annually.

Several integrating ideas have been developed to explain why tourists become the victims of criminal activity. One step towards formulating a more conceptual understanding of the tourists and criminal activities foisted on them can be found in a five part classification scheme also offered by Ryan (1993). One category identified by Ryan views tourists as incidental victims; here the crimes against them are not due to their tourist role but they are simply in a situation where anybody could have been a victim. A second category Ryan identified was later labelled as the crimogenic factor (Ryan and Kinder, 1996). In essence the term suggests tourist locations can become specific venues for crime. The kinds of location being specified as crimogenic include entertainment precincts where businesses meet the needs of large crowds of passing tourists. Such precincts include a mix of bars, nightclubs, markets, cheap shopping and gaming opportunities. Crime and tourism links 
may be thought of in these settings as involving multiple criminal activities including money laundering and, in some countries, prostitution and drug dealing. A third kind of link between tourists and crime is simply numerical; more tourists provide more people for criminals to prey upon. This category differs from the incidental tourist category since in this case the physically identifiable characteristics of those who are out of their normal surroundings makes them softer targets. Ryan's scheme does not neglect the direct involvement by tourists themselves in generating crime, particularly in creating a demand for stolen or pirated goods and possibly illegal services. Finally, the presence of tourists in prominent hotels, at attractions or at transport nodes can provide identifiable targets for public violence including individual acts of insanity and planned acts of terrorism.

Crotts (1996, 2011), amongst others, has used the notions of hot spot theory and the routine activities approach to describe the same kinds of tourism-crime links identified by Ryan. These two formulations can be seen as compatible with Ryan's work. For example, the concept of hot spots identifies specific locations within the crimogenic places where the criminal activity is most prevalent. Further, the routine activities approach suggests that criminals will exist whether tourists are present or not and that provided three enabling conditions are met (easy victims, motivated criminals and low levels enforcement) crime will take place. Tourists may or may not be the victims of these routine criminal efforts. The routine activities approach suggests that the extent to which tourists' appearance and behaviour single them out as easy targets will be correlated with the degree to which they are victims of attempted crimes.

\section{Tourist scams}

The specific interest in tourist scams in this study lies in a special component of the interaction which takes place in these encounters. A scam, as defined previously, involves fraudulent practice intended to gain financial advantage from a tourist where that targeted individual is initially a willing participant (Pearce, 2011). The distinguishing feature of the scam as opposed to any tourist directed crime is the initial willingness of the tourist to entertain the interaction and potentially seek to benefit or be personally advantaged by the encounter. In Italian, the term scam is best translated as "truffa" which equates to the English label of a "trick'; scams are indeed built on a trick. As an illustration, a tourist whose property is simply stolen is a criminal victim whereas a tourist who buys gemstones from a jewellery trader in the hope of profiteering by on-selling them, but who later finds that half are worthless because the vendor has substituted cheaper products in the package, is the victim of a tourist scam.

Stajano and Wilson (2009) note the use of a fairly widespread "trade" language to characterise the interacting personnel in these social situations. The tourists or target is referred to as the mark, the perpetrator is labelled the operator or sometimes the hustler, and if there are accomplices, they are known as the shills. Stajano and Wilson record some of the forces at work when scams have a social nature. Their work was based on a thorough analysis of the British TV documentary series The Real Hustle. The study was written by a computer scientist (Stajano) in collaboration with a professional hustler (Wilson) and was carried out to provide insights into human error underpinning computer security systems. They derived seven principles from their study of a considerable number of scams, some of which were tourist scams. Many of the other scams they describe involve extracting pin card numbers, using sleight of hand to play marks at games of chance and extracting money from shop assistants through fake authorisation from their bosses. The principles are summarised in Table 1.

Other studies on the nature of scams in general provide some psychological insight into the way individuals including tourists can be deceived. Researchers at the University of Exeter (2009), in a publication prepared for the British Office of Fair Trading, focussed attention on the motivational and cognitive drivers which lead to consumer involvement in scams. Their work was concerned principally with email approaches to consumers and suggested that 
Table 1. Seven principles leading to scam victimisation

\begin{abstract}
The distraction principle
While you are distracted by what retains your interest, hustlers can do anything to you and you won't notice

The social compliance principle

Society trains people not to question authority. Hustlers exploit this "suspension of suspiciousness" to make you do what they want.

The herd principle

Even suspicious marks will let their guard down when everyone next to them appears to share the same risks.

Safety in numbers? Not if they are all (shills) conspiring against you.

The dishonesty principle

Anything illegal you do will be used against you by the fraudster, making it harder for you to seek help once you realize you've been had.

The deception principle

Things and people are not what they seem. Hustlers know how to manipulate you to make you believe that they are.

\section{The need and greed principle}

Your needs and desires make you vulnerable. Once hustlers know what you really want, they can easily manipulate you.

The time principle

When you are under time pressure to make an important choice, you use a different decision strategy. Hustlers steer you towards a strategy involving less reasoning.
\end{abstract}

appeals to trust and authority were important in influencing participation in the activity. In their assessment of scams they identified greed, fear, and a desire to be liked as the foundations on which the operators were able to build their deceptive practices. The study which included experimental and questionnaire work conceived of scam involvement as errors in consumer judgement. They noted that the perpetrators were skilled in using authority criteria and that in their routines or trick they relied on the greed, fear and social needs of the targets.

The existing studies of scams are related to but not directed specifically at the topic of tourist scams. In order to meet the aims of the research and provide material for further consideration some original material on scams was collected.

\section{Method}

Four research assistants in collaboration with the author interviewed twelve personnel in Bangkok, Thailand. The city of Bangkok has an international reputation for high levels of localtourist interaction including sex tourism and plentiful night life (cf. Cohen, 1996; Howard, 2009). It offered the researchers an internationally popular location fitting the crimogenic label identified by Ryan and the classification of hot spots considered by Crotts and others. The range of individuals surveyed about the tourist scams in the Bangkok setting included the Thai police (2), the Thai tourist police (2), senior government personnel in the Tourism Authority of Thailand (4) and tourism academic researchers at the Assumption University of Thailand (4). Twelve separate interviews were conducted. The interviews were developed around a discussion which asked what tricks or scams directed at tourists were familiar to the interviewee. An emphasis was placed in the interviews on the types of scams rather than recalling specific scams although individual episodes were often highlighted. The information obtained was written down after the interview to avoid potentially disrupting the flow of the answers. Further components of the conversation sometimes involved those interviewed offering their views concerning who was to blame in the tourist scams and what precautions might be undertaken to prevent tourists falling for the schemes. The interview work was supplemented by the research team examining 30 postings about Thailand detailing individual travellers' experiences with criminal activities and scams (www.BangkokScam.com) accessed December 212010. 
These joint data acquisition processes identified 45 labelled episodes, although some of the activities noted were very similar such as taxi drivers, tuk tuk (a local form of transport) operators, guides and accommodation owners directing tourists into the shops of associates. The next step in the collection of information was to eliminate from the listing those activities where the victim's behaviour played no part in the fraud or deceit perpetrated against them. As an example, one of the situations reported on the site www.BangkokScam.com involves tourists renting jet skis in the resort of Pattaya. The criminal activity consists of the operators pointing to damage to the jet skis when they are returned and demanding restitution to the equivalent value of US $\$ 250$. If the tourists are unwilling to pay then the operators become physically intimidating and may call the police who are able to "negotiate" a settlement for a lesser but still palpably unwarranted amount of approximately US $\$ 175$. The suggestion that there is a criminal conspiracy with the police is a sensitive topic here but such claims by travellers experiencing this fraudulent set up appear to be repeated on numerous occasions (http://www.youtube.com/watch?v=zsPuoaktoAw).

Ten of the original 45 criminal or scam related episodes were removed from further consideration because the tourist was simply the (unwilling and unsuspecting) victim of a criminal or misleading act. This pivotal consideration was important in the study to be consistent with the organising definition"essentially fraudulent practice intended to gain financial advantage from a tourist where that targeted individual is initially a willing participant".

Even some of the remaining 35 cases collected in the interviews and noted from the travel blogs were challenging for the researchers to label as either scams or as direct crimes. In brief, the essence of the problem was attempting to determine whether the case did fall into the category of a scam where the tourist was partly at fault through gullible behaviour or by knowingly seeking to take advantage of others through a very cheap deal. The resolution to this dilemma in the present study was to determine that a scam was in operation if the tourist could be considered unlikely to undertake this behaviour in their own country. The researchers agreed with this criterion for the 35 instances which formed the basis of the final and core data set.

A three part coding scheme was developed to categorise the main themes in the scams. One group of scams related to deception in tourist service encounters including spa service, taxis, hotels, restaurants and petrol stations. A second category of scams summarised episodes to do with the retail environments. Both shopping in markets and purchasing products in more expensive stores (including purchasing products from tailors) were involved in this general retail category. A third group of tricks and scams was evident in interpersonal encounters where the social connections between tourists and the hustler were the basis of the deceptions and extortions. This category was labelled as social contact deception. One reviewer of this paper suggested that the term social contract might be equally applicable as a label for this grouping and indeed there is an implicit contract involved in the social situations portrayed. Some examples of scams in these categories are provided in Table 2.

The categorisation of the schemes into the themed areas is one approach to sorting the data that were collected in the study. Additionally the frequency of the scams is of interest as common scams may be more deserving of attention by tourism industry personnel and tourists themselves than are the infrequent and unusual operations. The actual frequency of the scams is very difficult to determine but the research assistants who were all living in Thailand and familiar with Thai culture rated the 35 scams on a 1 to 3 scale from very common to common to likely to occur occasionally. Collating this data produced the frequency information highlighted in Table 3.

It is notable that this material does not necessarily replicate the kinds of information reported in web sites such as leading scams in Thailand or other countries because such lists also contain the types of activities such as the fraudulent Jet Ski scenario which is not considered a scam within the definitional constraints of this paper. 
Tourist scams: exploring the dimensions of an international tourism phenomenon

Table 2. Illustrations of tourist scams in Thailand within a three part category scheme

\begin{abstract}
Tourist Services deception
Spa pricing: Tourists attracted to the use of spas in hotels reported that the bill for these services sometimes contained additional charges which were not clearly itemised at the time. Such charges included additions for special products used in the treatments plus a set of service and add on charges for laundry.
\end{abstract}

Taxis: In this scam airport taxi operators approach new arrivals and offer the cheapest fare into the city. By adding surcharges and tolls, tourists actually can pay considerably more than metered and regulated taxis.

Rental cars and petrol: Renting a vehicle is a popular activity but many motor scooters and some rental cars are not fitted with locks on the petrol tank. The scam consists of assuring the renter that the petrol is free and a part of the rental price. At popular attractions tourists sometimes return to their vehicle and find it without petrol but a nearby petrol station or service point is able to provide an "emergency supply" at a high price.

The fake reception call: Late in the evening the reception calls the hotel guest suggesting the need to recheck credit card numbers which were a little hard to read on the first scanning to get a recently announced discount. The guest is simply asked to read out the credit card number again then the eventual bill can be changed in their favour. The call is a fake and the provision of credit card details sets up the hustler with the bases for fake credit card production.

Cash confusions: Payment in an unfamiliar currency can lead to a suggestion that the tourist pay in cash US dollars or Euros and receive change in the same currency, thus saving on exchange rate conversions. The notes in US dollars or Euros which the hustler holds are counterfeit so all change from larger notes becomes a profit.

\title{
General Retail deception
}

The Thai gem scam: Tourists purchase what they believe to be good quality gems but in fact are sold inferior products. This may be because the gems are of low quality in the first place or there is a product substitution. There are multiple versions of this scam with varied other products from carpets to antiques, some of which come with supposedly valid authentication certificates.

Purchasing pirated goods: Tourists purchase goods (e.g. watches, handbags) they know to be copies of famous brands. At times the goods are so cheaply made that they fall apart or stop working within a short period of time.

Non-arrival of purchases: Items which are bulky or which take time to make are bought on a $50 \%$ down payment and $50 \%$ on receipt basis. The goods never arrive at the home destination thus leaving the tourist with little recourse except to write off the money initially spent.

\section{Social contact deception}

The friend and the police: Tourists are befriended by a local or locals and share an enjoyable evening or entertainment based outings. The tourist mark is then given pirated goods or drugs as a part of the friendship. Later police arrive at the hotel/accommodation location and search for the goods demanding payment to keep the matter quiet. The police may be corrupt officers or shills masquerading as police.

The tourist mark is seriously in trouble with this scam since large payments may be requested and if drugs are involved the potential consequences are extreme

The massage service extras: Male tourists in particular using massage services are the mark in this scheme which sees the legitimate body massage turn into the offer of sexual services. Customers refusing to pay the extra money and use the sexual services have their massage terminated and are asked to leave. Complaints about the exploitation are deflected by threatening the arrival of the police or private security and associated suggestions that the tourist will be accused of harassing the female staff member.

The international romance: Romantic attachments between the mark and the operator are built on time together and intimacies established during the tourist's holiday. There is the promise of a continuity of the relationship and further contact but requests for supporting money for the operator and her/his family are involved. The operator may be simultaneously having multiple international partners who are being exploited to varying degrees with promises of future contact and long term relationships. The cost to the mark here are financial and emotional and their culpability is testimony to the skill of the operator in building the trust in the relationship. 
Table 3. The 35 scams rated by local Thai resident research staff for likely frequency of occurring (1=very common, 2=common, 3=occasional)

\begin{tabular}{ll}
\hline $\begin{array}{c}\text { Mean } \\
\text { Frequency }\end{array}$ & Category of the scam \\
\hline 1.2 & Tourist services deception \\
1.3 & Tourist services deception \\
1.3 & Tourist services deception \\
1.4 & Tourist services deception
\end{tabular}

$\begin{array}{cc}1.5 & \text { Tourist services deception } \\ 1.5 & \text { Tourist services deception }\end{array}$

$1.8 \quad$ Tourist services deception

$1.8 \quad$ Tourist services deception

1.9 Tourist services deception

$2.2 \quad$ Tourist services deception

$2.2 \quad$ Tourist services deception

2.3 Tourist services deception

2.6 Tourist services deception

1.4 General retail deception

1.5 General retail deception

1.8 General retail deception

1.8 General retail deception

2.0 General retail deception

2.0 General retail deception

2.0 General retail deception

2.2 General retail deception

2.3 General retail deception

2.4 General retail deception

2.5 General retail deception

Tuk tuk drivers offering minimal fares -route goes to shops of associates

Taxis not using meters properly add extra or false amounts to bill

Using the large numbers associated with Thai money to give the wrong change such as for 500 Baht not 1000 Baht

Airport taxi services offered as special deal- car parking charge, tolls and extra services for bags make the fare considerably higher

Driver or guide claims that the attraction is closed -new route goes to shops of associates

Outside train stations, bus drivers falsely report that there are problems with the trains or that they are overbooked and that their bus is the fastest route

Cheap drinks are spiked to induce drowsiness thus making decisions poor or robbery easy

In bars where there are shows and performance the customer is offered cheap drinks but the bill includes the charge for the "free" show

Rental cars may be drained of petrol and high charges involved to refill the vehicle

Spa services on the hotel bill may be inflated with a large number of extra taxes and service charges

Prices advertised for restaurants are for locals but when tourists come to pay they are shown the price for foreigners

Restaurant adding a set of fake extra charges to bills for service, tips and special times

Fake calls from reception or hotel staff seek credit card detailslikely basis for reusing credit card

Copies of so called famous brands so cheaply made they fall apart almost immediately despite false guarantees of quality

Inferior materials used in products actually purchased such as cheaper material in clothes when superior materials were shown

Thai gem scams where quality gems are sometimes mixed with inferior gems to encourage purchasing

Services which are not requested such as wrapping purchases or placing them in carry bags attract extra charges

Goods ordered and part payment made but on return to pick up goods the stall or store has closed or no-one can contact the owner/operator

Non arrivals of purchases-items which are bulky and are freighted may be charged at $50 \%$ down payment and $50 \%$ on arrival. Goods never arrive overseas

Purchase of tour specifies certain destinations but these are not included due to "traffic" and substitutes are made to enhance shopping options

Authenticity of craft products is falsely promoted, not made in Thailand at all although the labels say so

Use of credit cards is charged at an unusually high additional percentage on top of the service

Up-selling of services places the individual in a difficult situation such as when sexual services are offered to massage clientsrefusal may difficult due to pressure or threats over inappropriate client behaviour

Some hotels operate on a different principle to western hotels and charge for guests to go into the occupant's room 
Social contact deception

1.3

Social contact deception

1.6

Social contact deception

1.9

Social contact deception

2.0

Social contact deception

2.4

Social contact deception

2.5

Social contact deception

Social contact deception

2.7

Social contact deception

3.0

Social contact deception

3.0

Social contact deception
Friendly Thai contact offers guiding services but really is a tout for shops and massage businesses

In a friendly way tourists are handed food to distribute to pigeons or birds and then charged

Bird droppings apparently fall on you in a narrow street. A concerned local happens to have a towel to assist you and while being helped your money passport are stolen

In bars drinks may be cheap but buying drinks for the female bar girls turns out to be quite expensive

Women interacting with men in massage parlours tell stories about their lives to extract financial support

Invitations for friendly locals lead to card games and loss of money in games that are set up.

A contact is made from a supposed hotel employee who is off duty and sees you leaving the hotel. This a set up to shopping scams, prostitution invites and other devious options

Friendships with locals are established and then the tourist is asked to buy drinks which turn out to be quite expensive

Slow build-up of contact with local turns into obligations to do favours such as accept or transport stolen or illegal goods

International romances established between Thais and foreigners may not be what they seem with multiple relationships being conducted and finances requested

Obligations to an intimate Thai friend turn out to be obligations to her family and relatives

\section{Discussion}

The coding scheme developed for the identification of the main categories of tourist scams was formulated as a simple three part system to capture the dominant instances recorded by the research team. Of the 35 scams identified in the study, there were often several variants of the same scam. For example, several versions of the taxi scam exist with incidents reported such as being taken to the wrong address and refusing non Thai currency thus requiring detours to obtain cash from disreputable money exchange venues. The three category schemes effectively accounted for all of the instances with the following frequency of allocation; tourist services deception 13, general retail deception 11, and social contact deception 11.

An important question to be raised in the context of the coding scheme is to what extent were there instances which did not fit readily into this three part category. This question prompts the further query of how likely is it that the categories derived from this study built on international tourism in Thailand apply to other settings, countries and continents? One set of tourists' blogs not easily incorporated into the coding scheme consisted of the identification of false advertising. The instances here include facilities in hotels which were promised but which were not open or available to guests. It was decided that these instances should not be identified as scams in the present study as the intention to defraud or mislead the customer was unclear. Other studies of tourists' scams might include this fourth category of "overpromising" to the tourist. An answer to the question of the international applicability of the three part coding scheme is problematic since it requires a parallel assessment of the range and scope of scams operating in other locations. International cases from other blog sites reporting tourist scams as well as tourist guide books carrying advice about local practices do seem to reiterate the themes used in the present study (cf. Howard, 2008).

A discussion concerning the attribution of responsibility is pertinent before any managerial advice to tourists or authorities to limit the operation of scams can be developed from this line of research. The attribution theory approach can be likened to a courtroom with accompanying rules of evidence to decide who is most responsible for the tourists' troubles. A consideration of both the tricks of the hustlers and the motivational patterns of those they 
exploit are on trial. It can be suggested that the fundamental attribution error comes into play when judging others and is likely to make us place more responsibility on the internal characteristics of others. This error is prevalent and occurs when external observers favour explanations of the behaviour of others in terms of internal factors rather than situational factors (Wiener, 2000, 2008). For example, the tourist whose wallet is stolen while he is in a crowded subway may be seen as negligent for not being more careful of his property. Individuals tend to explain their own behaviour in terms of a self serving heuristic with favourable outcomes attributed to themselves and unfavourable effects due to the situational factors (Hewstone, 1983; Siegel and Shaughnessy, 1996).

Thus while it is possible to acknowledge the role of the hustler and his or her shills in exploiting the tourist, external observers are also predisposed to relate to the stories of exploitation by assigning quite a bit of blame to the tourists (Pizam, Tarlow and Bloom, 1997). The consensus and consistency principle is used in many social judgements in these circumstances. A strong argument often used in these cases is that gullible tourists are at fault and that they get themselves into trouble. This is a responsibility attribution which permits public authorities to ignore some scam operators. On the other hand a widespread tourist attribution that many hustlers exist can lead to recommending that it is desirable to avoid contact with local people. This representation may be particularly damaging to the international appeal of a destination if it becomes enshrined in destination images.

Several strands of further academic work can be identified in the context of tourist scams, how attributions are made about them and the potential consequences which follow from those attributions. Further study could involve coding and categorising scams according to the frequency with which they use the principles outlined by Stajano and Wilson. In order to undertake this kind of work very specific instances of each tourist scam are needed as opposed to the more general recall of types of tourists scams discussed in the present paper. In order to pinpoint attributional concerns in a research context it would be advisable to use rich contextual material including descriptions of the participants and their travel experience and the physical settings in which they occur. It might be insightful to use visual images and photographs of the scams such as are depicted in some of the web site advice about avoiding scams to make the attributions meaningful and the situations credible for the research respondents.

Additionally, as outlined succinctly in the previous paragraphs, the internet description and commentary on tourist scams is a source of research information. Using naturalistic data of this type could be productive in classifying the kinds of attributional statements made in commentary on others' experiences. The value of using naturalistic data in accounting for explanations has been recognised for some time and methods to assess the available information have been proposed (Harvey et al., 1988). Further, studies could be built by taking versions of tourist scenarios and asking select groups with varying levels of involvement and authority to consider who should be held accountable for troubling outcomes. Such studies may provide subtle insight into some of the public debates about who should be responsible for and what actions should be taken to promote safer tourism settings. Tourist scams are at one end of a spectrum of threats to tourists' good times and their further study could usefully explore the exact influence mechanism which underpins them. Such operational information combined with an understanding of the motives, character strengths, and personalities of those who get involved may also be insightful for both future travellers and site managers.

\section{Conclusion}

The scenarios identified in this study of tourist scams represent a comprehensive collection of episodes likely to trouble tourists. The sources of information used to identify these scams included key informants as well as examples drawn from web sites reporting such challenging and essentially exploitative interactions. The specialised use of the term tourist scams in this study restricted the treatment of the phenomenon to those settings 
where there was at least some potential culpability for the encounter resting with the tourists' behaviour. This distinction was considered to be important to distinguish the scams from the larger category of negative encounters broadly represented by the previous literature on crimes against tourists. In pursuing the nature of tourist scams in Thailand as a particular setting for the study of this topic, it was suggested that the three categories of scams can be usefully identified- tourism services deception, general retail deception and social contact deception. Further in the context of Thailand the specific frequency of these scams was able to be identified by a small set of local informants and the potentially powerful role of attribution theory in developing work in this area was suggested. The core approach and findings from this study might serve as a useful category scheme as well as a thorough description of scams and therefore be a benchmark for subsequent research in this area of tourist concern.

\section{References}

Ambinder, E. (1992). Urban violence raises safety fears. Corporate Travel 9(6), p. 10.

Chesney-Lind, M., and Lind, I. (1986). Visitors as victims: Crimes against tourists in Hawaii. Annals of Tourism Research 13(2), 167192.

Cohen, E. (1996). Touting tourists in Thailand; tourist-oriented crime and social structure. In A. Pizam and J. Mansfeld (eds.) Tourism, Crime and International Security Issues. New York: Wiley, pp. 77-90.

Crotts, C. (1996). Theoretical perspectives on tourist criminal victimisation. Journal of Tourism Studies 7(1), 2-9.

Crotts, J. (2011). Serendipitous gleanings. In P.L. Pearce (ed.) The Study of Tourism Foundations from Psychology. New York: Elsevier, pp. 230-254.

De Albuquerque, K. and McElroy, J. (1999). Tourism and Crime in the Caribbean. Annals of Tourism Research 26(4), 968-984.

Ferreira, S. L. A. (1999). Crime; a threat to tourism in South Africa. Tourism Geographies 1(3), 313-324.

George, R. (2003). Tourists' perceptions of safety and security while visiting Cape Town. Tourism Management 24(5), 575-585.

George, R. (2010). Visitor perception of crime-safety and attitudes towards risk: the case of
Table Mountain National Park, Cape Town. Tourism Management 31(6), 806-815.

Harvey, J. H., Turnquist, D. and Agostinelli, G. (1988). Identifying attributions in written and oral explanations. In C. Antaki (ed.) Analysing everyday explanations. London: Sage, pp. 32-42.

Hewstone, M. (1983). Attribution theory and common-sense explanations an introductory overview in M Hewstone (ed.) Attribution theory. Oxford: Basil Blackwell, pp. 1-24.

Howard, R. W. (2009). Risky business? Asking tourists what hazards they actually encountered in Thailand. Tourism Management 30(3), 359-365.

McElroy, J.L., Tarlow, P. and Carlisle, K. (2008). Tourist harassment and responses. In A. Woodside and D. Martin (eds.) Tourism Management Analysis, Behaviour and Strategy. Wallingford, Oxon: CABI, pp.94106.

Michalko, G. (2003). Tourism eclipsed by crime; the vulnerability of foreign tourists in Hungary. In C. M. Hall, D. J. Timothy, and D. T. Duval (eds.) Safety and security in Tourism. New York: Haworth Hospitality Press, pp.159172.

Pearce, P. L. (2011). Tourist Behaviour and the Contemporary World. Bristol: Channel View.

Pizam, A and Mansfeld, J. (eds.) (2006). Tourism Security and Safety: From Theory to Practice. New York: John Wiley.

Pizam, A., Tarlow, P. and Bloom, J. (1997). Making tourists feel safe; whose responsibility is it? Journal of Travel Research 36(1), 23-29.

Ryan, C. (1993). Crime, violence, terrorism and tourism an accidental or intrinsic relationship? Tourism Management 14(3), 173-183.

Ryan, C and Kinder, R. (1996). The deviant tourist and the crimogenic place-the case of the tourist and the New Zealand prostitutue. In A. Pizam and J. Mansfeld (eds.) Tourism, Crime and International Security Issues. New York: Wiley, pp. 37-49.

Siegel, J. and Shaughnessy, M. F. (1996). An interview with Bernard Weiner. Educational Psychology Review 8(2), 165-174.

Weiner, B. (2000). Attributional thoughts about consumer behaviour. The Journal of Consumer Research 27(3), 382-387.

Weiner, B. (2008). Reflections on the history of attribution theory and research. Social Psychology, 39(3), 151-156. 